\title{
Uncovering unseen fungal diversity from plant DNA banks
}

\author{
Erin M Datlof ${ }^{1}$, Anthony S Amend ${ }^{1}$, Kamala Earl ${ }^{2}$, Jeremy Hayward ${ }^{1}$, Clifford W Morden ${ }^{1}$, Rachael Wade ${ }^{1}$ \\ , Geoffrey Zahn ${ }^{1}$, Nicole A Hynson ${ }^{\text {Corresp. } 1}$ \\ 1 Department of Botany, University of Hawai'i at Mānoa, Honolulu, HI, United States \\ 2 School of Forest Resources and Conservation, University of Florida, Gainesville, FL, United States \\ Corresponding Author: Nicole A Hynson \\ Email address: nhynson@hawaii.edu
}

Throughout the world DNA banks are used as storage repositories for genetic diversity of organisms ranging from plants to insects to mammals. Designed to preserve the genetic information for organisms of interest, these banks also indirectly preserve organisms' associated microbiomes, including fungi associated with plant tissues. Studies of fungal biodiversity lag far behind those of macroorganisms, such as plants, and estimates of global fungal richness are still widely debated. Utilizing previously collected specimens to study patterns of fungal diversity could significantly increase our understanding of overall patterns of biodiversity from snapshots in time. Here, we investigated the fungi inhabiting the phylloplane among species of the endemic Hawaiian plant genus, Clermontia (Campanulaceae). Utilizing next generation DNA amplicon sequencing, we uncovered approximately 1,780 fungal operational taxonomic units, from just 20 DNA bank samples collected throughout the main Hawaiian Islands. Using these historical samples, we tested the macroecological pattern of decreasing community similarity with decreasing geographic proximity. We found a significant distance decay pattern among Clermontia associated fungal communities. This study provides the first insights into elucidating patterns of microbial diversity through the use of DNA bank repository samples. 


\section{Uncovering unseen fungal diversity from plant DNA banks}

2 Erin M. Datlof ${ }^{1}$, Anthony S. Amend ${ }^{1}$, Kamala Earl ${ }^{2}$, Jeremy Hayward ${ }^{1}$, Clifford W. Morden ${ }^{1}$,

3 Rachael Wade ${ }^{1}$, Geoffrey Zahn ${ }^{1}$, Nicole A. Hynson ${ }^{1}$

$4{ }^{1}$ Department of Botany, University of Hawai ‘i at Mānoa, Honolulu, HI, United States

$5 \quad{ }^{2}$ School of Forest Resources and Conservation, University of Florida, Gainesville, FL, United

6 States

7

8 Corresponding Author:

9 Nicole A. Hynson ${ }^{1}$

10 Department of Botany, University of Hawai'i at Mānoa, Honolulu, HI, 96822, United States

11 Email address: nhynson@hawaii.edu

12

13

14

15

16

17

18

19

20

21

22 


\section{Abstract}

25

Throughout the world DNA banks are used as storage repositories for genetic diversity of organisms ranging from plants to insects to mammals. Designed to preserve the genetic information for organisms of interest, these banks also indirectly preserve organisms' associated microbiomes, including fungi associated with plant tissues. Studies of fungal biodiversity lag far behind those of macroorganisms, such as plants, and estimates of global fungal richness are still widely debated. Utilizing previously collected specimens to study patterns of fungal diversity could significantly increase our understanding of overall patterns of biodiversity from snapshots in time. Here, we investigated the fungi inhabiting the phylloplane among species of the endemic Hawaiian plant genus, Clermontia (Campanulaceae). Utilizing next generation DNA amplicon sequencing, we uncovered approximately 1,780 fungal operational taxonomic units, from just 20 DNA bank samples collected throughout the main Hawaiian Islands. Using these historical samples, we tested the macroecological pattern of decreasing community similarity with decreasing geographic proximity. We found a significant distance decay pattern among Clermontia associated fungal communities. This study provides the first insights into elucidating patterns of microbial diversity through the use of DNA bank repository samples.

\section{Introduction}

Understanding biodiversity is an important goal of Biology. This is particularly critical in a changing world with habitat degradation and fragmentation, population declines, and species extinctions (Vitousek et al., 1997). Once a species becomes extinct, the genetic history resulting from its evolution is lost as well (Mattick et al., 1992). DNA banks were initially developed to collect genetic material to create a storage base for evolutionary history, biological diversity, and 
47 genomic information (Mattick et al., 1992). Throughout the world, samples are collected and 48 stored in these banks to document and preserve genetic diversity (Spooner \& Ruess, 2014). For 49 extinct species, DNA bank samples act as storage deposits for their genomes (Adams, 1994; 50 Spooner \& Ruess, 2014).

In addition to the importance of DNA bank repositories for archiving target organisms' genetic information, these samples also harbor the microbial diversity associated with each accession. These samples represent well-preserved DNA at snapshots in time and space. For example, plant DNA bank samples not only preserve the genomic information of the targeted species', but also preserve potentially important cryptic microbial symbionts associated with the host, such as fungi known to inhabit the plant phyllosphere (Porras-Alfaro \& Bayman, 2011; Vorholt, 2012).

Despite much work on patterns of plant diversity, comparatively little is known about the diversity of fungi. Fungi play crucial functions in ecosystems by acting as decomposers and nutrient cyclers, important mutualists such as mycorrhizae, and pathogens influencing host species populations (Kendrick, 2001; Lips et al., 2006). Globally, <100,000 species of fungi have been described (Blackwell, 2011), which is far less than total estimated fungal diversity, and also less than vascular plants, with $<400,000$ species currently described (Royal Botanic Gardens Kew, 2016). Estimates of global fungal species richness have increased almost 3-5 fold in the past 20 years, from 1.5 million (Hawksworth, 1991) to 3.5-6 million species (O’Brien et al., 2005; Taylor et al., 2014). This increase is due in part to advances in direct environmental DNA sequencing and extrapolations based on predictions of vascular plant to fungal ratios (O'Brien et al., 2011; Taylor et al., 2014). In order to obtain more accurate estimates of true fungal diversity, increased sampling using high throughput DNA sequencing of many different types of 
70 environments is needed, and DNA banks may significantly contribute to filling this knowledge 71 gap.

Hawai' $i$ is a biodiversity hotspot, making it an exceptional location to study patterns of species diversity (Myers et al., 2000). However, we know very little about Hawaiian fungi, their potential rates of endemism, and patterns of biodiversity. A survey of mushrooms throughout the Hawaiian Islands conducted in the 90 's found 310 species. The majority of these taxa were introduced, however 52 were putatively native and 46 of these taxa were considered potentially endemic ( $\sim 88 \%$; Hemmes and Desjardin 2002). Similar rates of endemism are found in the Hawaiian flora.

An estimated $89 \%$ of the Hawaiian vascular plant flora is endemic (Wagner et al., 1999).

The unique Hawaiian flora is threatened by habitat degradation and loss, coupled with species invasions, which have led to native species becoming endangered or extinct (Morden, Caraway \& Motley, 1996). There are currently 1,175 recognized native (endemic plus indigenous)

83 Angiosperm species in Hawai ${ }^{`} i$ (Smithsonian Institution, 2017) and 422 of these plants are currently endangered (35.9\%; US Fish \& Wildlife, 2015) with 104 taxa extinct or possibly extinct (8.8\%; Sakai, Wagner \& Mehrhoff, 2002). As a result of these extinctions and a strong potential for additional future losses, the Hawaiian Plant DNA Library (HPDL) was created to 87 preserve the genetic diversity of the Hawaiian flora (Morden, Caraway \& Motley, 1996). The HPDL was started in 1992 and currently has over 10,000 accessions representing over $86 \%$ of all of the Hawaiian plant genera and over $50 \%$ of all species. Similar to other DNA

90 banks across the world, collections for common species contain multiple individuals with their

91 own accession number. However, the HPDL is unique due to the relatively disproportionate

92 number of threatened and endangered native Hawaiian plants compared to other localities, and 
93 thus serves as a genetic repository for many species that are endangered or extinct in the wild

94 (Morden, Caraway \& Motley, 1996). The main goal of the HPDL is to preserve Hawaiian plant

95 DNA and bank samples for use in future studies of biodiversity (Morden, Caraway \& Motley,

96 1996; Randell \& Morden, 1999).

97 All naturally occurring plant tissues harbor fungi as both endophytes, living in between

98 plant cells (Rodriguez et al., 2009) and epiphytes, living on plant surfaces (Santamaría \&

99 Bayman, 2005) collectively known as phyllosphere fungi (Vacher et al., 2016). These

100 communities form diverse assemblages with some studies showing an average of about 100

101 species per tree and ranges of about 700-4,000 species of fungi per host species (Jumpponen \&

102 Jones, 2009; Zimmerman \& Vitousek, 2012). Thus, along with the HPDL's banked plant

103 samples it also has likely and coincidentally preserved a substantial portion of the diversity of

104 Hawaiian fungi, acting as a repository for not only plant genetics, but their microbiomes as well.

105 Utilizing several plant bank samples from the HPDL we investigated the diversity of

106 unintentionally co-sampled fungi found within banked plant samples through space.

107 Phyllosphere fungal communities can be cryptic and hyperdiverse (Jumpponen \& Jones, 2009;

108 Zimmerman \& Vitousek, 2012) and this poses a challenge to studies with the goal of assessing

109 microbial diversity. Even with the adoption of next generation DNA sequencing technologies,

110 such as high throughput amplicon sequencing from environmental samples, observed diversity is

111 often an under representation of true diversity (Chiu \& Chao 2016). Thus, rather than

112 superficially sequencing the fungi from all available replicate DNA extracts from a single plant

113 species, we chose to deeply sequence ten samples of a common endemic Hawaiian plant genus,

114 Clermontia (Campanulaceae), with species found across the Hawaiian Islands (Givnish et al., 
115 2009). This deep sequencing was done in hopes that the vast majority of fungi from our samples

116 would be recovered from each sample across this spatial range.

117 In this study, we utilized historical DNA bank samples to validate the use of plant bank

118 samples as a resource for elucidating phyllosphere fungal biodiversity, while subsequently

119 examining plant-associated fungal diversity across space. Our two main questions were do DNA

120 bank samples store microbial diversity? And can these previously collected samples be used to

121 uncover ecological patterns, such as changes in microbial community similarity over space? As a

122 model plant system, we selected a single endemic Hawaiian plant genus, Clermontia, found

123 across the Hawaiian Islands. Using DNA samples of eight species within this genus stored in the

124 HPDL, we sequenced the fungi found in these plants' phylloplanes (the portion of the

125 phyllosphere made up by leaves). We took advantage of the archipelago's geographic spatial

126 gradient and the previously collected samples in the HPDL to test for decreases in community

127 similarity as the distance between communities increases, the classical ecological pattern of

128 distance-decay of community similarity (Nekola \& White, 1999).

130 Materials \& Methods

131 SamplesWe examined foliar DNA extracts stored in the HPDL from the genus

132 Clermontia, representing eight species collected from Hawai'i Island, O`ahu, Maui, Moloka'i

133 and Kaua'i (Table 1.; see Supplementary Table S1. for more details). When initial collections

134 were made, young leaf samples were collected in the field without the use of gloves, sealed in

135 bags, and stored at $4^{\circ} \mathrm{C}$ until DNA extraction (less than a week). Leaves were not disturbed by

136 rinsing prior to DNA extraction. Approximately $1.0 \mathrm{~g}$ of leaf tissue was extracted using a

137 modified CTAB method with cesium chloride banding optimized to recover high quality DNA 
138 intended for long-term storage, and stored at $-20^{\circ} \mathrm{C}$ (Doyle \& Doyle, 1987; Morden, Caraway \&

139 Motley, 1996) until aliquots were taken for analyses. Samples used in this study were in the -

$14020^{\circ} \mathrm{C}$ freezer ranging from 2-10 years. Two individual plant DNA extracts of each species per

141 location were equally pooled, yielding a total of ten samples from 20 Clermontia individuals $(n=$

142 10), with C. kakeana replicates on three different islands: O`ahu, Moloka'i, and Maui.

144 PCR and Sequencing

145 These pooled extracts were individually prepared for fungal DNA sequencing with slight

146 modifications to the Illumina 16S Metagenomic Sequencing Library Preparation protocol using a

147 two-step PCR and index attachment (Illumina, 2015). Fungal DNA amplicons of the $\sim 250-400$ -

148 bp targeted nuclear ribosomal Internal Transcribed Spacer 1 (ITS1) locus were amplified using

149 ITS1F primers with Illumina adapter overhangs (5'Adapter-

150 CTTGGTCATTTAGAGGAAGTAA-3'; Gardes \& Bruns, 1993) and modified ITS2 primers

151 (5'Adapter-GCTGCGTTCTTCATCGATGC-3'; White et al., 1990). The ITS locus is the official

152 fungal DNA barcode (Schoch et al., 2012). Amplicons were purified and size-selected using

153 SPRIselect beads (Beckman Coulter, Inc.), followed by a second PCR attaching forward and

154 reverse eight-base pair barcoded Illumina overhang adapters (i7 and i5; Illumina, 2015). See

155 Supplementary Table S2 for PCR recipes and thermalcycler parameters. These indexed libraries

156 were bead purified and quantified using the Qubit dsDNA HS kit (Life Technologies Inc.

157 Gaithersburg, MD, USA). Libraries were then pooled at equimolar concentrations and sent to the

158 Hawai' $i$ Institute for Marine Biology Genetics Core Facility (HIMB) for quality control on the

159 Agilent 2100 Bioanalyzer (Agilent Technologies, Santa Clara, CA, USA) and sequencing on the

160 Illumina MiSeq platform v.3 paired-end 2x300 (Illumina, San Diego, CA, USA). 


\section{Bioinformatics}

163 De-multiplexed fastq files were obtained from the sequencing facility from the ten

164 Clermontia plant bank samples. Raw sequencing data was deposited to the National Center for

165 Biotechnology Information Sequence Read Archive (NCBI SRA) under BioProject

166 PRJNA379349. These paired-end reads were merged with the Illumina Paired-End reAd mergeR

167 (PEAR), keeping reads with a minimum assembly length of 250-bp, average quality threshold of

16815 and above, and discarding all reads with any uncalled bases (Zhang et al., 2014). Further

169 quality control was carried out using the FASTX-Toolkit, using the fastq quality_filter

170 command (Hannon Lab, 2016), where all reads with any base pairs containing a quality score

171 below 15 were discarded (Hannon Lab, 2016). Potential chimeras were removed in vsearch

172 (Rognes et al., 2016) using the uchime_ref command (Edgar et al., 2011), which referenced the

173 User-friendly Nordic ITS Ectomycorrhiza (UNITE) database, accessed on 11.03.2015 (Kõljalg et

174 al., 2013). Operational Taxonomic Units (OTUs) were clustered within QIIME (Caporaso et al.,

175 2010) using the open-reference method (Navas-Molina et al., 2013) following the Usearch

176 algorithm (Edgar, 2010). Briefly, reads were matched to reference OTUs in the UNITE dynamic

177 database (ver7) (Kõljalg et al., 2010) with added Clermontia outgroups, then remaining reads

178 that failed to match were subsampled as seeds for three subsequent rounds of de novo OTU-

179 picking. The most abundant sequence for each OTU was chosen as a representative sequence.

180 Singleton reads were removed in QIIME prior to OTU table generation and taxonomy was

181 assigned against the UNITE database with the Basic Local Alignment (BLAST) algorithm.

182

183 Statistics 
All statistical analyses were conducted in R version 3.3.0 (R Core Team, 2017). The

185 OTU table from QIIME was imported into R with the package biomformat (McMurdie \&

186 Paulson, 2016). OTUs that mapped to plant taxonomies or those that had no BLAST hit were

187 removed from the OTU matrix and all OTUs with greater than ten reads were kept for analyses.

188 Samples were rarefied to 16,546 reads, the minimum sample depth. Rarefaction, species

189 accumulation curves were generated using the vegan package for: all samples, individual

190 samples, and samples pooled by island (Oksanen et al., 2017). Because observed species richness

191 often under estimates true species richness (Hughes et al., 2001), asymptotic extrapolations of

192 species richness and diversity for all samples and species were estimated based on the first three

193 Hill numbers using the iNEXT package for raw incidence data (Hsieh, Ma \& Chao, 2016). These

194 are namely species richness, the exponential of Shannon entropy, and the inverse Simpson

195 concentration, represented by $q=0,1,2$, respectively (Chao et al., 2014). Hill numbers and

196 extrapolations were generated based on individual samples and individual species. A Venn

197 diagram was generated to visualize overlapping taxa between islands using the VennDiagram

198 package (Chen, 2016).

199

200

Distance matrices

201 To investigate ecological patterns, we accounted for variables that may be influencing the

202 fungal communities found in these banked samples. These factors were temporal and physical

203 distances between sample collections, as well as fungal community dissimilarity. Pairwise

204 distance matrices were calculated for physical distance in kilometers using the geosphere

205 package (Hijmans, 2016), time between sample collections in days, and Bray-Curtis community

206 dissimilarity using the vegan package (Oksanen et al., 2017). Separate Mantel tests for each 
207 combination of the following pairwise distance matrices: time between sample collections

208 (days), as well as Euclidean physical distance between samples ( $\mathrm{km})$, and community

209 dissimilarity (Bray-Curtis), were run for 10,000 permutations. To investigate the effects of these

210 variables a final partial Mantel test for physical distance and community dissimilarity, while

211 controlling for time, was run for 10,000 permutations (Oksanen et al., 2017).

213 Results

214 Sequencing

215 A total of 4,312,473 sequence reads were obtained from the plant DNA library samples.

216 Of these, 3,571,252 paired-end reads (82.8\%) were successfully assembled and further quality

217 control removed low quality reads, keeping 2,680,945 reads (75.1\%). After referencing UNITE,

$218121,618(4.5 \%)$ chimeric sequences were removed, leaving a total of 2,559,327 high-quality

219 reads. Taxonomic assignment yielded a total of 1,648,971 fungal reads that were binned into

2202,944 fungal OTUs for use in in downstream analyses.

221

222 Fungal diversity and host associations

223 Each Clermontia DNA bank sample used in this study contained fungal DNA. In total, 224 we found 2,944 fungal OTUs associated with the ten foliar DNA bank samples. After removing 225 OTUs with less than ten reads and rarefying to the sample with the minimum number of reads, 226 we removed 1,164 OTUs (39.5\%) and were left with a total of 1,780 fungal OTUs. While the 227 observed OTU accumulation curve for all ten samples combined did not reach an asymptote 228 (Figure S1), OTU accumulation curves by sample, and by island (except in the case of $C$. fauriei 229 from Kaua'i and C. kakeana Moloka'i) generally reached their asymptotes, indicating that 
230 overall, we successfully recovered the majority of fungi present in our samples (Figures S2 and

231 S3). Observed richness per sample after rarefying, ranged from 108 to 682 fungal OTUs with an

232 average of 295 OTUs per sample ( \pm 54.69 standard error). From our ten samples combined the

233 iNEXT extrapolation curves suggest fungal richness based on the Hill number $q=0$ (Chao1

234 richness) will saturate around 3,947 OTUs which would require at least 50 samples. Similarly

235 fungal diversity based on $q=1$ (exponential Shannon entropy) was estimated to saturate at

236 around 2,750, and diversity based on $q=2$ (inverse Simpson concentration) was estimated to

237 saturate at about 1,591 (Figure 1).

238 We investigated patterns of fungal diversity at the phyla and ordinal levels. Overall, the

239 majority of fungi in the subkingdom Dikarya dominated all of the phylloplane samples, with

240 phylum Ascomycota being most abundant, followed by Basidiomycota (Figures 2). Fungi

241 belonging to the phylum Chytridiomycota and Zygomycota were also present in lower

242 abundances. Additional OTUs mapped to kingdom Fungi but could not be identified further

243 (Unidentified; Figure 2). The top ten most abundant orders were Capnodiales, Chaetothyriales,

244 Exobasidiales, Peltigerales, Pertusariales, Pleosporales, Tremellales, Ustilaginales, and two

245 unknown orders (Figure 3).

246 Based on our observed data, total average fungal OTU richness by island was $507.6( \pm$

247128.46 standard error). O`ahu had the highest total observed richness with 1,045 OTUs, followed

248 successively by Hawai'i (926 OTUs), Maui (685 OTUs), Moloka'i (362 OTUs), and Kaua'i

249 again had the lowest richness (108 OTUs), though unlike the other islands we did not saturate

250 our OTU richness by sequencing effort curve for $C$. fauriei from Kaua'i and C. kakeana from

251 Moloka' $\mathrm{i}$ indicating that these are an underrepresentation of fungal OTU richness (Figure S3).

252 Overall about twenty OTUs were found on all of the five islands (Figure 4). 
254

255

256

257

258

259

260

261

262

263

264

265

266

267

268

269

270

271

272

273

274

275

Physical distance decay

Clermontia DNA bank extracts used in this study spanned across the main Hawaiian Islands. The nearest samples were collected less than one kilometer apart from a single site in Kohala, Hawai' $i$ Island, and the furthest distance was $524.78 \mathrm{~km}$ from Kohala, Hawai' $i$ Island to the Alaka'i Swamp, Kaua'i. Over this spatial range, while taking into account time (number of days) between sample collections, the fungal phylloplane communities exhibit a significant decrease in community similarity across increasing geographic distance (Figure 5, Partial Mantel test: $r=0.423, p=0.005)$. Time, calculated as days between plant sample collection, was also significantly correlated with physical distance between sample sites (Figure S4, Mantel test: $r=$ $0.455, p=0.048)$. Time between sampling and community dissimilarity was marginally significantly correlated (Figure S5, Mantel test: $r=0.619, p=0.051$ ). Despite the significant relationships with sampling time, the Partial Mantel between distance and community dissimilarity, while accounting for time, was very significant (Figure 5).

\section{Discussion and Conclusion}

In this study, we investigated the diversity of phylloplane fungi associated with Clermontia spp. that were collected across the Hawaiian Islands and stored as DNA bank samples. While sample collection methods were not developed with the intention of preserving or analyzing phyllosphere fungi, they coincide with common practices for these purposes (Jumpponen \& Jones, 2009; Zimmerman \& Vitousek, 2012) and despite the use of protection from potential contaminants through the use of gloves or surface sterilization, we were able to detect a stronger signal through this additional noise. 
We found that these specimens harbored a considerable diversity of fungi. After quality

277

278

279

280

281

282

283

284

285

286

287

288

289

290

291

292

293

294

295

296

297

control, we found 1,780 fungal OTUs from just ten samples, representing 20 Clermontia

individuals and eight species. Fungal richness ranged from 108 to 682 OTUs per plant sample.

Incredibly, this diversity was recovered from a total of just 20 grams of leaf tissue from which

DNA was extracted and preserved. Despite high sequencing depth, the species accumulation

curve for all samples and islands did not saturate, indicating this sequencing effort likely

underestimated true Clermontia phylloplane fungal diversity. However, this novel use of DNA

bank samples revealed substantial undiscovered fungal biodiversity stored in plant samples.

These results provide further evidence of microbes making up the "unseen majority" of

biodiversity (Whitman, Coleman \& Wiebe, 1998), where a single macroorganism associates with

a multitude of microorganisms both within and on their surfaces (Turner, James \& Poole, 2013).

This study highlights a new and underutilized function of biological collections, as well

as gives insights into regional fungal diversity patterns. Previous estimates of total regional

fungal richness have been based off of plant to fungi ratios ranging from 1:6 (Hawksworth,

1991) to 1:17 (Taylor et al., 2014). Our data supplement these studies using environmental NGS

data. If we assume that the diversity of phylloplane fungi associated with Clermontia species is

representative of the native Hawaiian flora, we would estimate based on Chao 1 richness $(q=0)$

extrapolations (determined by species; Figure S6) that the entire Hawaiian flora (c. 1,000

species) harbors about 4,000 fungi. This results in an approximate 1:4 plant to fungi species

ratio. However, just considering phylloplane fungi associated with a single genus is likely an

underestimate of total fungal biodiversity due to potential host-fungi specificity (Hoffman \&

Arnold, 2008). Supplementary to host specificity, only taking into consideration phylloplane

PeerJ reviewing PDF | (2017:04:17770:2:0:CHECK 2 Aug 2017) 
298 fungi likely underestimates total regional fungal richness due to habitat niche partitioning among

299 fungal species and guilds (Hibbett, Gilbert \& Donoghue, 2000).

300 In addition to the study of microbial diversity, questions regarding microbial

301 biogeography, host specificity, and the effects of global change on microbial communities could

302 be addressed with DNA banks. For example, we were able to confirm the distance decay of

303 microbial community similarity from DNA bank samples collected across the Hawaiian Islands.

304 This finding is similar to other microbial systems where significant distance decay patterns were

305 found in foliar endophytic (Vaz et al., 2014) and ectomyorrhizal fungal communities (Bahram et

306 al., 2013), as well as bacteria and archaea (Barreto et al., 2014). We were also able to identify a

307 temporal partitioning of phylloplane fungal communities (Figure S5), indicating that DNA bank

308 collections may be used to study changes in microbial communities over time. However, in

309 addition to geography and temporal factors, taking into account host genotype, age, specificity,

310 and differences in environment, such as light exposure and humidity, may potentially explain

311 additional variation in fungal communities (Hoffman \& Arnold, 2008).

312 In agreement with other phyllosphere studies, the majority of fungal taxa were identified

313 as belonging to the subkingdom Dikarya, with the majority of fungi in phylum Ascomycota

314 followed by Basidiomycota (Rodriguez et al., 2008). It is not surprising that we found so many

315 unknown fungal taxa ( $45.16 \%$ of total OTUs at the family level) including 28 OTUs we were

316 unable to place at the phylum level. The plant samples from this study represent an endemic

317 Hawaiian genus whose microbial associates are previously unstudied, and possibly associate

318 with undescribed fungi endemic to Hawai' $\mathrm{i}$. However, this degree of unassigned fungal OTUs is

319 not unique to our system and highlights our limited current knowledge of fungal diversity

320 (Nilsson et al., 2016). For example, recent discoveries using environmental DNA sequencing 
321 have reshaped the fungal tree of life, uncovering a new fungal Phylum, the Cryptomycota (Jones

322 et al., 2011). This stresses the need for further investigations of fungal biodiversity, their cryptic

323 nature and diverse functions make for intriguing new discoveries that have the potential to

324 change evolutionary and ecological theories based primarily on macroorganisms.

325

With the recent advent of next generation sequencing (NGS) techniques genomic

326 investigations of non-model organisms have become readily accessible (da Fonseca et al., 2016).

327 However, there are important caveats to consider when using these methods and analyses. For

328 example, working with environmental samples poses the challenging prospect of encountering

329 hyperdiverse microbial communities such as the fungi found here, and other studies of plant

330 phyllosphere fungi (Arnold, 2007; Arnold \& Lutzoni, 2007). As seen in this NGS study,

331 thousands of fungi can be associated with a small number of plant leaf samples. While

332 uncovering this diversity is a goal of some microbial ecologists, for researchers using NGS

333 techniques focused on the host organism (in this case plants), microbial symbionts may interfere

334 with downstream analyses and results. Microbial taxa associated with macroorganismns should

335 be taken into account when using NGS methods such as RAD seq, RNA seq, targeted

336 sequencing, among other techniques (da Fonseca et al., 2016). Additionally, future research into

337 the microbiomes of hosts preserved in DNA banks should take into consideration how sample

338 processing and storage may affect microbes. When initially collecting samples for these

339 purposes, care should be taken to avoid microbial contamination from non-target hosts or

340 environments.

341 Most DNA bank samples likely harbor unintended microbial communities associated

342 with each target individual from a specific location at distinct snapshots in time. While DNA

343 banks are a common genetic biodiversity repository (Seberg et al., 2016), to the best of our 
344 knowledge this is the first study where they were used to investigate genetic material other than

345 that of the target organism. By using these archived samples we were able to rapidly recover

346 previously undocumented microbial diversity. The abundance of DNA bank samples stored

347 throughout the world represent a large proportion of the globes extant and extinct biological

348 diversity. This storage provides the opportunity for microbes associated with these organisms to

349 be easily investigated without the associated costs of sample collection. This may be important

350 for conservation efforts, giving insight into potentially important symbionts (van der Heijden,

351 Bardgett \& Straalen, 2008; Busby et al., 2016). For those species that go extinct, their genomes

352 are preserved in DNA banks along with their corresponding microbial symbionts. For extant

353 organisms, DNA bank samples could be used to better understand the ecology of symbiosis and

354 possibly identify coevolutionary patterns. Overall, this study highlights the potential use of DNA

355 bank samples for the study of global biodiversity. This study also demonstrates the benefits of in-

356 depth sample sequencing to uncover the majority of fungal diversity found in each plant bank

357 sample. With DNA bank samples stored throughout the world, already collected, processed, and

358 extracted, they harbor the potential for new and exciting investigations.

359

\section{Acknowledgements}

361 We thank Emily Johnston and Richard O'Rorke for experimental and lab help, further lab

362 assistance by Leah Tooman. Also thanks to Sean Swift, Laura Tipton, and Sofia Gomes for R

363 help. Thanks to Mitsuko Yorkston and Richard Pender for sample discussions. We would also

364 like to thank Ricardo Araujo and two additional anonymous reviewers for their helpful

365 suggestions on a previous version of this manuscript. 


\section{References}

368 Adams RP. 1994. DNA Bank-Net - An overview. In: Adams RP., Miller JS., Golderberg EM.,

369 Adams JE., eds. Conservation of Plant Genes II: Utilization of Ancient and Modern DNA.

370 St. Louis: Monographs in Systematic Botany from the Missouri Botanical Garden, 1-13.

371 Arnold AE. 2007. Understanding the diversity of foliar endophytic fungi: progress, challenges, 372 and frontiers. Fungal Biology Reviews 21:51-66.

373 Arnold AE., Lutzoni F. 2007. Diversity and host range of foliar fungal endophytes: are tropical $374 \quad$ leaves biodiversity hotspots? Ecology 88:541-549.

375 Bahram M., Kõljalg U., Courty P-E., Diédhiou AG., Kjøller R., Põlme S., Ryberg M., Veldre V.,

376 Tedersoo L. 2013. The distance decay of similarity in communities of ectomycorrhizal

377 fungi in different ecosystems and scales. Journal of Ecology 101:1335-1344.

378 Barreto DP., Conrad R., Klose M., Claus P., Enrich-Prast A. 2014. Distance-Decay and Taxa379 Area Relationships for Bacteria, Archaea and Methanogenic Archaea in a Tropical Lake $380 \quad$ Sediment. PLoS ONE 9:e110128.

381 Blackwell M. 2011. The Fungi: 1, 2, 3 ... 5.1 million species? American Journal of Botany $38298: 426-438$.

383 Busby PE., Ridout M., Newcombe G. 2016. Fungal endophytes: modifiers of plant disease. Plant 384 Molecular Biology 90:645-655.

385 Caporaso JG., Kuczynski J., Stombaugh J., Bittinger K., Bushman FD., Costello EK., Fierer N., 386 Peña AG., Goodrich JK., Gordon JI., Huttley GA., Kelley ST., Knights D., Koenig JE., 387 Ruth LE., Lozupone CA., McDonald D., Muegge BD., Pirrung M., Reeder J. 2010. QIIME 388 allows analysis of high-throughput community sequencing data. Nature Methods 7:335-336. 
389 Chao A., Gotelli NJ., Hsieh TC., Sander EL., Ma KH., Colwell RK., Ellison AM. 2014.

390 Rarefaction and Extrapolation with Hill Numbers: A Framework for Sampling and

391 Estimation in Species Diversity Studies. Ecological Monographs 84: 45-67.

392 Chen H. 2016. VennDiagram: Generate High-Resolution Venn and Euler Plots. R package

393 version 1.6.17. Available at https://CRAN.R-project.org/package=VennDiagram.

394 Chiu C-H., Chao A. Estimating and comparing microbial diversity in the presence of sequencing 395 errors. PeerJ 4:e1634. DOI 10.7717/peerj.1634.

396 da Fonseca RR., Albrechtsen A., Themudo GE., Ramos-Madrigal J., Sibbesen JA., Maretty L.,

397 Zepeda-Mendoza ML., Campos PF., Heller R., Pereira RJ. 2016. Next-generation biology:

398 Sequencing and data analysis approaches for non-model organisms. Marine Genomics 30:3$399 \quad 13$.

400 Doyle JJ., Doyle JL. 1987. A rapid DNA isolation procedure for small quantities of fresh leaf 401 tissue. Photochemical Bulletin 19:11-15.

402 Edgar RC. 2010. Search and clustering orders of magnitude faster than BLAST. Bioinformatics $403 \quad 26: 2460-2461$.

404 Edgar RC., Haas BJ., Clemente JC., Quince C., Knight R. 2011. UCHIME improves sensitivity 405 and speed of chimera detection. Bioinformatics 27(16):2194-2200.

406 Gardes M., Bruns M. 1993. ITS primers with enhanced specificity for Basidiomycetes 407 Application to the identification of mycorrhizae and rusts. Molecular Ecology 2:113-118. 408 Givnish TJ., Millam KC., Mast AR., Paterson TB., Theim TJ., Hipp AL., Henss JM., Smith JF., 409 Wood KR., Sytsma KJ. 2009. Origin, adaptive radiation and diversification of the Hawaiian 410 lobeliads (Asterales: Campanulaceae). Proceedings of the Royal Society B: Biological $411 \quad$ Sciences 276:407-416. 
412 Hannon Lab. 2016. FASTX-Toolkit: FASTQ/A short-reads pre-processing tools. Available at 413 http://hannonlab.cshl.edu/fastx_toolkit/.

414 Hawksworth DL. 1991. The fungal dimension of biodiversity: magnitude, significance, and $415 \quad$ conservation. Mycological Research 6:641-655.

416 Hemmes DE., Desjardin DE. 2002. Mushrooms of Hawai'i. Introduction. Berkeley: Ten Speed $417 \quad$ Press, 8-9.

418 Hibbett DS., Gilbert L-B., Donoghue MJ. 2000. Evolutionary instability of ectomycorrhizal 419 symbioses in basidiomycetes. Nature 407:506-508.

420 Hijmans RJ. 2016. geosphere: Spherical Trigonometry. R package version 1.5-5. Available at 421 https://CRAN.R-project.org/package=geosphere.

422 Hoffman MT., Arnold AE. 2008. Geographic locality and host identity shape fungal endophyte 423 communities in cupressaceous trees. Mycological Research 112:331-344.

424 Hsieh TC., Ma KH., Chao A. 2016. iNEXT: iNterpolation and EXTrapolation for species 425 diversity. R package version 2.0.12. Available at http://chao.stat.nthu.edu.tw/blog/software426 download/.

427 Hughes JB., Hellmann JJ., Ricketts TH., Bohannan BJM. 2001. Counting the Uncountable: 428 Statistical Approaches to Estimating Microbial Diversity. Applied and Environmental $429 \quad$ Microbiology 67:4399-4406.

430 Illumina. 2013. 16S Metagenomic Sequencing Library Preparation. Illumina Inc. Available at 431 http://support.illumina.com/downloads/16s_metagenomic_sequencing_library_preparation. 432 html. (Accessed January 2015). 
433 Jones MDM., Forn I., Gadelha C., Egan MJ., Bass D., Massana R., Richards TA. 2011.

434 Discovery of novel intermediate forms redefines the fungal tree of life. Nature 474: 200435203.

436 Jumpponen A., Jones KL. 2009. Massively parallel 454 sequencing indicates hyperdiverse 437 fungal communities in temperate Quercus macrocarpa phyllosphere. New Phytologist $438 \quad 184: 438-448$.

439 Kendrick B. 2001. The Fifth Kingdom. Mycologue Publications. Ontario: Mycologue $440 \quad$ Publications.

441 Kõljalg U., Nilsson RH., Abarenkov K., Tedersoo L., Taylor AFS., Bahram M., Bates ST., Bruns 442 TD., Bengtsson-Palme J., Callaghan TM., Douglas B., Drenkhan T., Eberhardt U., Dueñas 443 M., Grebenc T., Griffith GW., Hartmann M., Kirk PM., Kohout P., Larsson E., Lindahl 444 BD., Lücking R., Martín MP., Matheny PB., Nguyen NH., Niskanen T., Oja J., Peay KG., 445 Peintner U., Peterson M., Põldmaa K., Saag L., Saar I., Schüßler A., Scott JA., Senés C., 446 Smith ME., Suija A., Taylor DL., Telleria MT., Weiß M., Larsson K-H. 2013. Towards a 5277.

Lips KR., Brem F., Brenes R., Reeve JD., Alford RA., Voyles J., Carey C., Livo L., Pessier AP., 450 Collins JP. 2006. Emerging infectious disease and the loss of biodiversity in a Neotropical 451 amphibian community. Proceedings of the national academy of sciences of the United States of America 103:3165-3170.

Mattick JS., Ablett EM., Edmonson DL. 1992. The Gene Library - Preservation and Analysis of 454 Genetic Diversity in Australasia. In: Adams RP., Adams JE., eds. Conservation of Plant 455 Genes: DNA Banking and in vitro Biotechnology. San Diego: Academic Press, 15-35. 
456 McMurdie PJ., Paulson, JN. 2016. biomformat: An interface package for the BIOM file format. 457 Available at https://github.com/joey711/biomformat/, http://biom-format.org.

458 Morden CW., Caraway V., Motley TJ. 1996. Development of a DNA library for native Hawaiian 459 plants. Pacific Science 50:324-335.

460 Morden CW. 2017. Hawaiian Plant DNA Library. Available at 461 http://www.botany.hawaii.edu/hawaiian-plant-dna-library/. (Accessed 15 April 2017)

462 Myers N., Mittermeier RA., Mittermeier CG., Da Fonseca GA., Kent J. 2000. Biodiversity 463 hotspots for conservation priorities. Nature 403:853-858.

464 Navas-Molina JA., Peralta-Sánchez JM., González A., McMurdie PJ., Vázquez-Baeza Y., Xu Z., 465 Ursell LK., Lauber C., Zhou H., Song SJ., Huntley J., Ackermann GL., Berg-Lyons D., 466 Holmes S., Caporaso JG., Knight R. 2013. Advancing Our Understanding of the Human 467 Microbiome Using QIIME. Methods in Enzymology. Elsevier, 371-444.

468 Nekola JC., White PS. 1999. The distance decay of similarity in biogeography and ecology. $469 \quad$ Journal of Biogeography 26:867-878.

470 Nilsson RH., Wurzbacher C., Bahram M., R. M. Coimbra V., Larsson E., Tedersoo L., Eriksson 471 J., Duarte C., Svantesson S., Sánchez-García M., Ryberg MK., Kristiansson E., Abarenkov $472 \quad$ K. 2016. Top 50 most wanted fungi. MycoKeys 12:29-40.

473 O’Brien HE., Parrent JL., Jackson JA., Moncalvo J-M., Vilgalys R. 2005. Fungal Community 474 Analysis by Large-Scale Sequencing of Environmental Samples. Applied and $475 \quad$ Environmental Microbiology 71:5544-5550.

476 Oksanen J., Blanchet FG., Friendly M., Roeland K., Legendre P., McGlinn D., Minchin PR., 477 O'Hara RB., Simpson GL., Solymos P., Stevens MHH., Szoecs E., Wagner H. 2017. vegan: 
Community Ecology Package. R package version. 2.4-2. Available at https://CRAN.Rproject.org/package=vegan.

Porras-Alfaro A., Bayman P. 2011. Hidden Fungi, Emergent Properties: Endophytes and Microbiomes. Annual Review of Phytopathology 49:291-315.

482

483

484

485

486

487

488

489

490

491

492

493

494

495

496

497

498

499

500

R Core Team. 2017. R: A language and environment for statistical computing. R Foundation for Statistical Computing, Vienna, Austria. Available at https://www.R-project.org/.

Randell RA., Morden CW. 1999. Hawaiian Plant DNA Library II: Endemic, Indigenous, and Introduced Species. Pacific Science 53:401-417.

Rodriguez RJ., White Jr JF., Arnold AE., Redman RS. 2009. Fungal endophytes: diversity and functional roles. New Phytologist 182:314-330.

Rognes T., Flouri T., Nichols B., Quince C., Mahé F. 2016. VSEARCH: a versatile open source tool for metagenomics. PeerJ Preprints 4:e2409v1.

Royal Botanic Gardens Kew. 2016. State of the World's Plants Report - 2016. Royal Botanic Gardens, Kew.

Sakai AK., Wagner WL., Mehrhoff LA. 2002. Patterns of endangerment in the Hawaiian flora. Systematic biology 51:276-302.

Santamaría J., Bayman P. 2005. Fungal Epiphytes and Endophytes of Coffee Leaves (Coffea arabica). Microbial Ecology 50:1-8.

Schoch CL., Seifert KA., Huhndorf S., Robert V., Spouge JL., Levesque CA., Chen W., Fungal Barcoding Consortium, Fungal Barcoding Consortium Author List, Bolchacova E., Voigt K., Crous PW., Miller AN., Wingfield MJ., Aime MC., An K-D., Bai F-Y., Barreto RW., Begerow D., Bergeron M-J., Blackwell M., Boekhout T., Bogale M., Boonyuen N., Burgaz AR., Buyck B., Cai L., Cai Q., Cardinali G., Chaverri P., Coppins BJ., Crespo A., Cubas P., 
501 Cummings C., Damm U., de Beer ZW., de Hoog GS., Del-Prado R., Dentinger B., Dieguez-

502 Uribeondo J., Divakar PK., Douglas B., Duenas M., Duong TA., Eberhardt U., Edwards

503 JE., Elshahed MS., Fliegerova K., Furtado M., Garcia MA., Ge Z-W., Griffith GW.,

504 Griffiths K., Groenewald JZ., Groenewald M., Grube M., Gryzenhout M., Guo L-D., Hagen

505 F., Hambleton S., Hamelin RC., Hansen K., Harrold P., Heller G., Herrera C., Hirayama K.,

506 Hirooka Y., Ho H-M., Hoffmann K., Hofstetter V., Hognabba F., Hollingsworth PM., Hong

507 S-B., Hosaka K., Houbraken J., Hughes K., Huhtinen S., Hyde KD., James T., Johnson

508 EM., Johnson JE., Johnston PR., Jones EBG., Kelly LJ., Kirk PM., Knapp DG., Koljalg U.,

509 Kovacs GM., Kurtzman CP., Landvik S., Leavitt SD., Liggenstoffer AS., Liimatainen K.,

510 Lombard L., Luangsa-ard JJ., Lumbsch HT., Maganti H., Maharachchikumbura SSN.,

511 Martin MP., May TW., McTaggart AR., Methven AS., Meyer W., Moncalvo J-M.,

512 Mongkolsamrit S., Nagy LG., Nilsson RH., Niskanen T., Nyilasi I., Okada G., Okane I.,

513 Olariaga I., Otte J., Papp T., Park D., Petkovits T., Pino-Bodas R., Quaedvlieg W., Raja

514 HA., Redecker D., Rintoul TL., Ruibal C., Sarmiento-Ramirez JM., Schmitt I., Schussler

515 A., Shearer C., Sotome K., Stefani FOP., Stenroos S., Stielow B., Stockinger H., Suetrong

516 S., Suh S-O., Sung G-H., Suzuki M., Tanaka K., Tedersoo L., Telleria MT., Tretter E.,

517 Untereiner WA., Urbina H., Vagvolgyi C., Vialle A., Vu TD., Walther G., Wang Q-M.,

518 Wang Y., Weir BS., Weiss M., White MM., Xu J., Yahr R., Yang ZL., Yurkov A., Zamora

519 J-C., Zhang N., Zhuang W-Y., Schindel D. 2012. Nuclear ribosomal internal transcribed

520 spacer (ITS) region as a universal DNA barcode marker for Fungi. Proceedings of the

$521 \quad$ National Academy of Sciences 109:6241-6246. 
522 Seberg O., Droege G., Barker K., Coddington JA., Funk V., Gostel M., Petersen G., Smith PP.

523 2016. Global Genome Biodiversity Network: saving a blueprint of the Tree of Life - a

$524 \quad$ botanical perspective. Annals of Botany 118:393-399.

525 Smithsonian Institution. 2017. Flora of the Hawaiian Islands. Available at

526 http://botany.si.edu/pacificislandbiodiversity/hawaiianflora/query2.cfm?radio (Accessed 23

527 March 2017).

528 Spooner DM., Ruess, H. 2014. Curating DNA specimens. In: Applequist WL., Campbell LM.,

529 eds. DNA Banking for the $21^{\text {st }}$ Century. St. Louis: William L. Brown Center, 71-80.

530 Taylor DL., Hollingsworth TN., McFarland JW., Lennon NJ., Nusbaum C., Ruess RW. 2014. A

531 first comprehensive census of fungi in soil reveals both hyperdiversity and fine-scale niche

532 partitioning. Ecological Monographs 84:3-20.

533 Turner TR., James EK., Poole PS. 2013. The plant microbiome. Genome biology 14:209.

534 US Fish and Wildlife Service. 2015. Listed species believed to or known to occur in Hawaii.

535 Available at https://ecos.fws.gov/ecp0/reports/species-listed-by-state-

536 report $?$ state $=$ HI\&status $=$ listed $($ Accessed 23 March 2017).

537 Vacher C., Hampe A., Porté AJ., Sauer U., Compant S., Morris CE. 2016. The Phyllosphere:

538 Microbial Jungle at the Plant-Climate Interface. Annual Review of Ecology, Evolution, and

$539 \quad$ Systematics 47:1-24.

540 van der Heijden MGA., Bardgett RD., van Straalen NM. 2008. The unseen majority: soil

541 microbes as drivers of plant diversity and productivity in terrestrial ecosystems. Ecology

$542 \quad$ Letters 11:296-310.

543 Vaz ABM., Fontenla S., Rocha FS., Brandão LR., Vieira MLA., de Garcia V., Góes-Neto A.,

544 Rosa CA. 2014. Fungal endophyte $\beta$-diversity associated with Myrtaceae species in an 
545 Andean Patagonian forest (Argentina) and an Atlantic forest (Brazil). Fungal Ecology 8:28-

54636.

547 Vitousek PM., Mooney HA., Lubchenco J., Melillo JM. 1997. Human domination of Earth’s $548 \quad$ ecosystems. Science 277:494-499.

549 Vorholt JA. 2012. Microbial life in the phyllosphere. Nature Reviews Microbiology 10:828-840.

550 Wagner WL., Herbst DR., Sohmer SH. 1999. Manual of the flowering plants of Hawai'i. In:

551 Mill SW., ed. Summary and brief analysis of the Hawaiian flora. Honolulu: University of

552 Hawai`i Press and Bishop Museum Press, 3-6.

553 White TJ., Bruns T., Lee S., Taylor JW. 1990. Amplification and direct sequencing of fungal

554 ribosomal RNA genes for phylogenetics. In: Innis, MA., Gelfand DH., Sninsky JJ., White

555 TJ, eds. PCR Protocols: A Guide to Methods and Applications. New York: Academic Press, $556 \quad$ Inc, $315-322$.

557 Whitman WB., Coleman DC., Wiebe WJ. 1998. Prokaryotes: The unseen majority. Proceedings $558 \quad$ of the National Academy of Sciences 95:6578-6583.

559 Zhang J., Kobert K., Flouri T., Stamatakis A. 2014. PEAR: a fast and accurate Illumina Paired-

$560 \quad$ End reAd mergeR. Bioinformatics 30:614-6.

561 Zimmerman NB., Vitousek PM. 2012. Fungal endophyte communities reflect environmental

562 structuring across a Hawaiian landscape. Proceedings of the National Academy of Sciences

$563 \quad 109: 13022-13027$.

564

565

566 


\section{Tables and Figures}

569

570 Table 1: DNA bank samples and accession numbers from the HPDL for each extract along with

571 associated metadata. In this study, two individual extracts were pooled for each location and 572 given a sample code labeled by island.

573

\begin{tabular}{|c|c|c|c|c|c|c|c|}
\hline Sample & $\begin{array}{c}\text { Sample } \\
\text { Code }\end{array}$ & $\begin{array}{c}\text { HPDL } \\
\text { Number }\end{array}$ & Clermontia species & Island & $\begin{array}{c}\text { Date } \\
\text { Extracted }\end{array}$ & Latitude & Longitude \\
\hline 1 & \multirow[t]{2}{*}{ M1 } & 6843 & \multirow[t]{2}{*}{ kakeana } & \multirow[t]{2}{*}{ Moloka'i } & \multirow[t]{2}{*}{$7 / 14 / 11$} & \multirow[t]{2}{*}{21.13} & \multirow[t]{2}{*}{-156.92} \\
\hline 1a & & 6844 & & & & & \\
\hline 2 & \multirow[t]{2}{*}{$\mathrm{H} 1$} & 6961 & \multirow[t]{2}{*}{ calophylla } & \multirow[t]{2}{*}{ Hawai' $i$} & \multirow[t]{2}{*}{$11 / 18 / 11$} & \multirow[t]{2}{*}{20.09} & \multirow[t]{2}{*}{-155.74} \\
\hline $2 \mathrm{a}$ & & 6962 & & & & & \\
\hline 3 & \multirow[t]{2}{*}{$\mathrm{H} 2$} & 6888 & \multirow[t]{2}{*}{ kohalae } & \multirow[t]{2}{*}{ Hawai' ${ }^{\top} \mathrm{i}$} & \multirow[t]{2}{*}{$9 / 17 / 11$} & \multirow[t]{2}{*}{20.08} & \multirow[t]{2}{*}{-155.74} \\
\hline $3 a$ & & 6889 & & & & & \\
\hline 4 & \multirow[t]{2}{*}{$\mathrm{H} 3$} & 6856 & \multirow[t]{2}{*}{ clermoniotides } & \multirow[t]{2}{*}{ Hawai' $i$} & \multirow[t]{2}{*}{$8 / 3 / 11$} & \multirow[t]{2}{*}{19.21} & \multirow[t]{2}{*}{-155.60} \\
\hline $4 a$ & & 6857 & & & & & \\
\hline 5 & \multirow[t]{2}{*}{$\mathrm{H} 4$} & 7339 & \multirow{2}{*}{$\begin{array}{l}\text { peleana ssp. } \\
\text { singulariflora }\end{array}$} & \multirow[t]{2}{*}{ Hawai ${ }^{\circ} \mathrm{i}$} & \multirow[t]{2}{*}{$6 / 7 / 13$} & \multirow[t]{2}{*}{20.18} & \multirow[t]{2}{*}{-155.80} \\
\hline $5 \mathrm{a}$ & & 7940 & & & & & \\
\hline 6 & \multirow[t]{2}{*}{ K1 } & 5089 & \multirow[t]{2}{*}{ fauriei } & \multirow[t]{2}{*}{ Kaua' ${ }^{i}$} & \multirow[t]{2}{*}{$9 / 6 / 05$} & \multirow[t]{2}{*}{22.09} & -159.59 \\
\hline 6а & & 5090 & & & & & \\
\hline 7 & O1 & 6809 & kakeana & O'ahu & $6 / 17 / 11$ & 21.34 & -157.82 \\
\hline $7 \mathrm{a}$ & & 6810 & & & & & \\
\hline 8 & $\mathrm{O} 2$ & 7008 & oblongifolia ssp. & O'ahu & $3 / 15 / 12$ & 21.41 & -158.10 \\
\hline $8 \mathrm{a}$ & & 7009 & & & & & \\
\hline 9 & Ma1 & 6875 & arborescens & Maui & $7 / 5 / 11$ & 20.82 & -156.28 \\
\hline $9 \mathrm{a}$ & & 6876 & & & & & \\
\hline 10 & Ma2 & 6831 & kakeana & Maui & $7 / 14 / 11$ & 20.80 & -156.23 \\
\hline $10 \mathrm{a}$ & & 6832 & & & & & \\
\hline
\end{tabular}




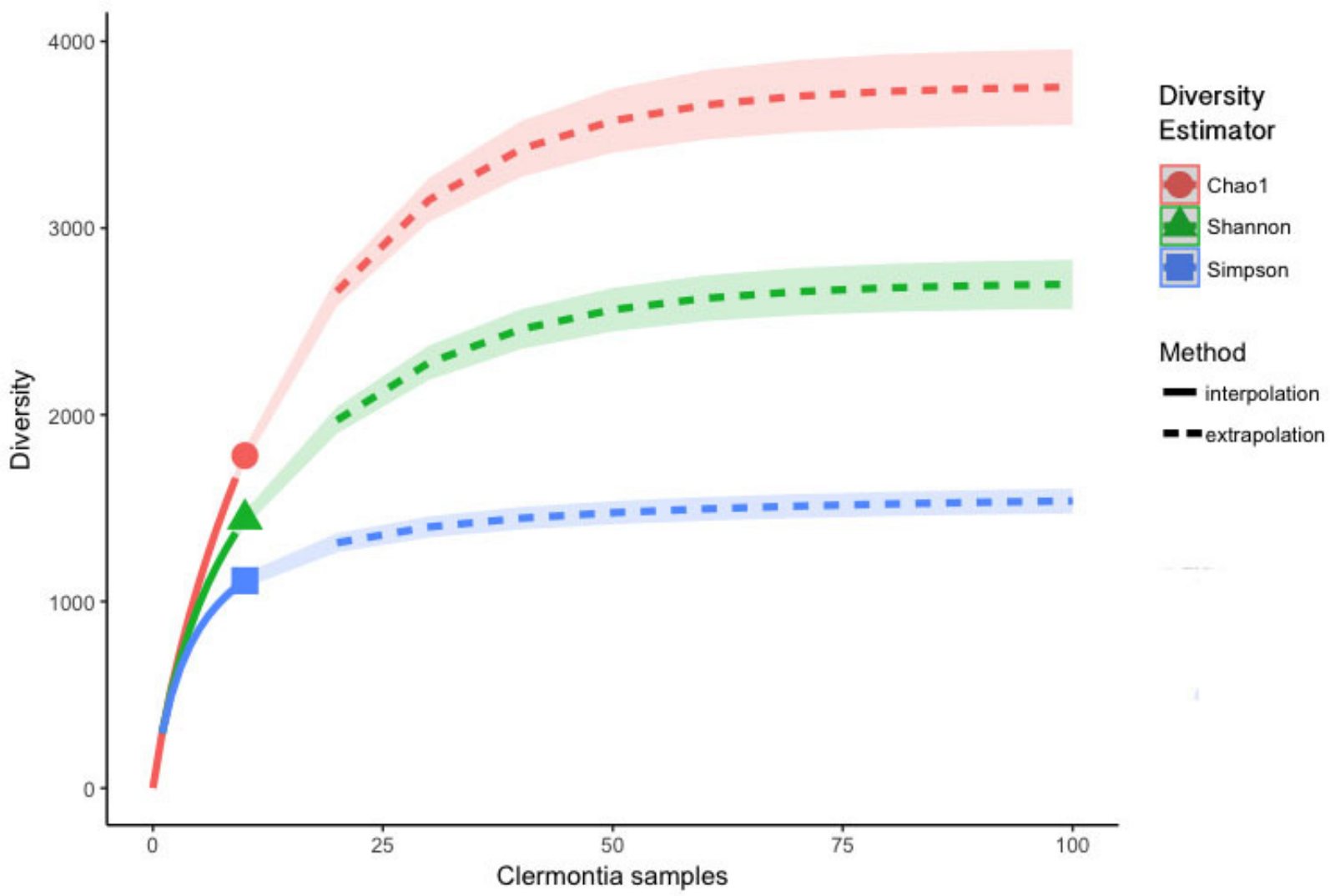

575 Figure 1: Sample interpolation (solid lines) and extrapolation (dashed lines) curves for phylloplane fungi from all ten Clermontia DNA bank samples. Based Hill's numbers three different diversity estimators were used (Chao1 richness, exponential of Shannon entropy, and inverse Simpson concentration indices) and are shown by the different colors with 95\% confidence intervals shown by shading. Shapes represent observed phylloplane fungal OTU diversity for the ten samples of Clermontia spp. 


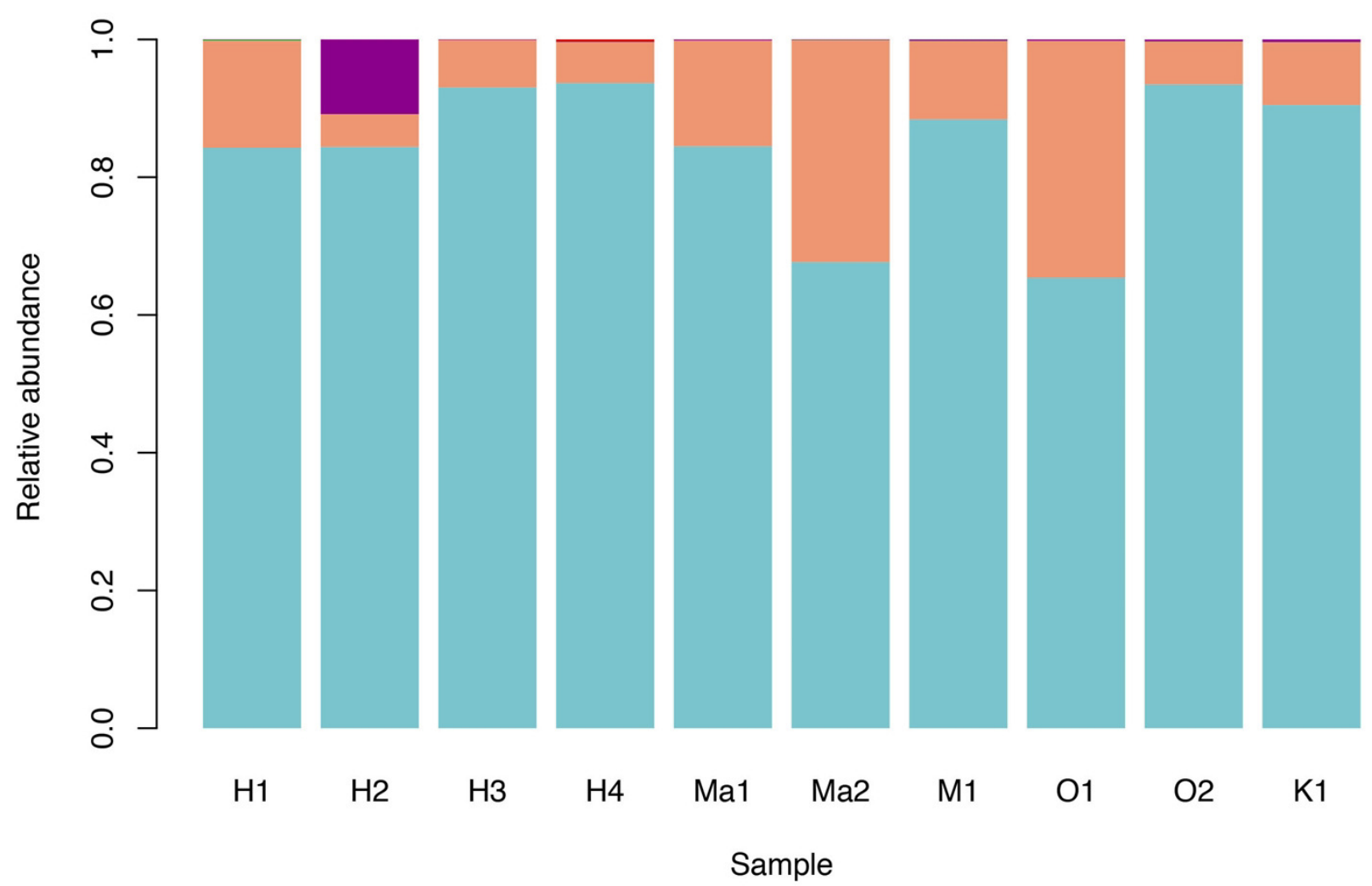

Phylum

$\square$ Ascomycota
$\square$ Basidiomycota
$\square$ Chytridiomycota
$\square$ unidentified
$\square$ Zygomycota

583 Figure 2: Relative abundances of fungal phyla for each Clermontia DNA bank sample. 


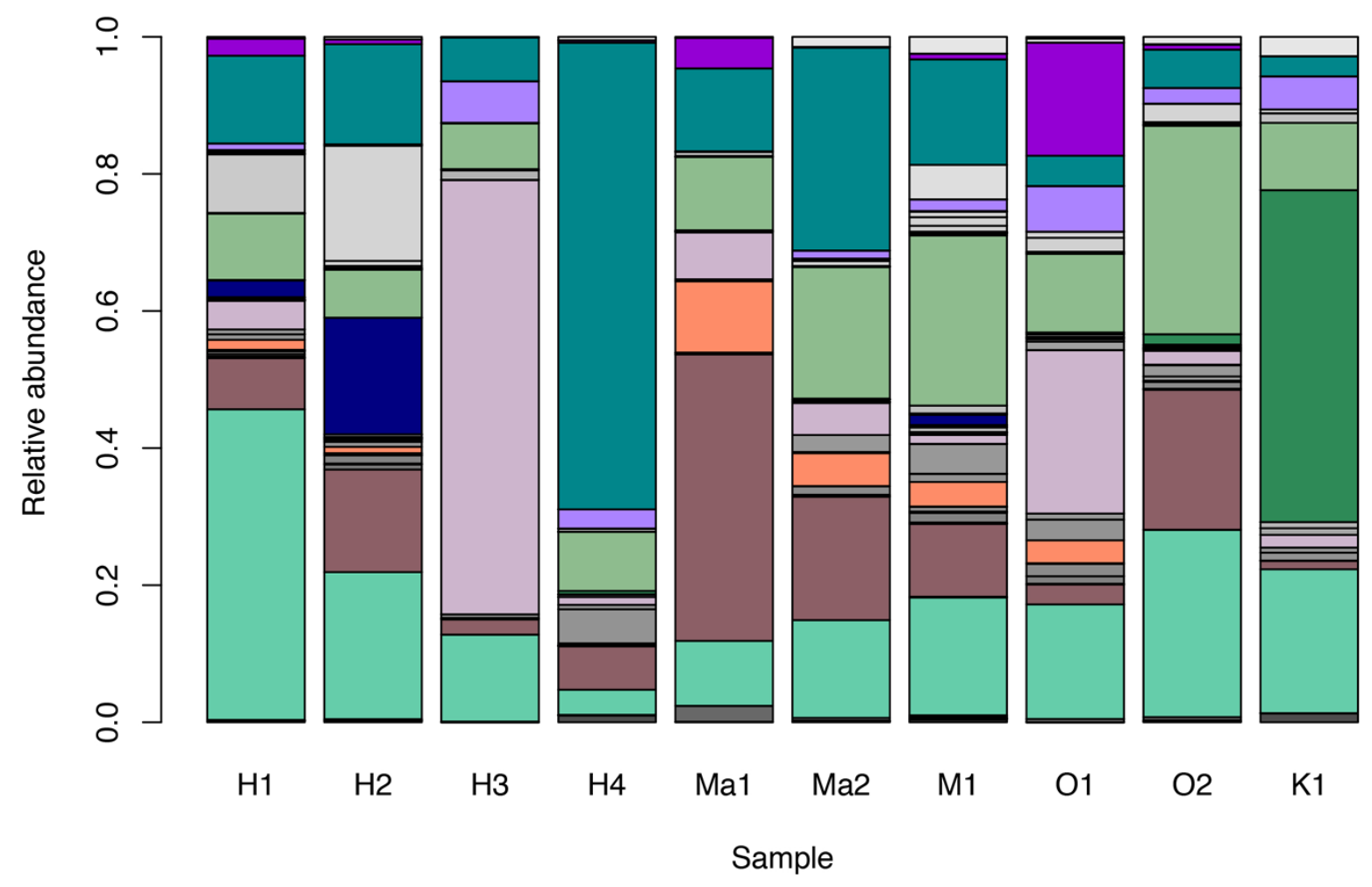

584

585

586

587

588

Order

$\square$ Capnodiales $\square$ Pertusariales
$\square$ Chaetothyriales $\square$ Pleosporales
$\square$ Exobasidiales $\square$ Tremellales
$\square$ Incertae sedis $\square$ Unidentified
$\square$ Peltigerales $\quad \square$ Ustilaginales

Figure 3: Relative abundances of the top ten most abundant fungal orders for each Clermontia DNA bank sample represented by color bars. The less abundant orders are represented by grayscale bars. 

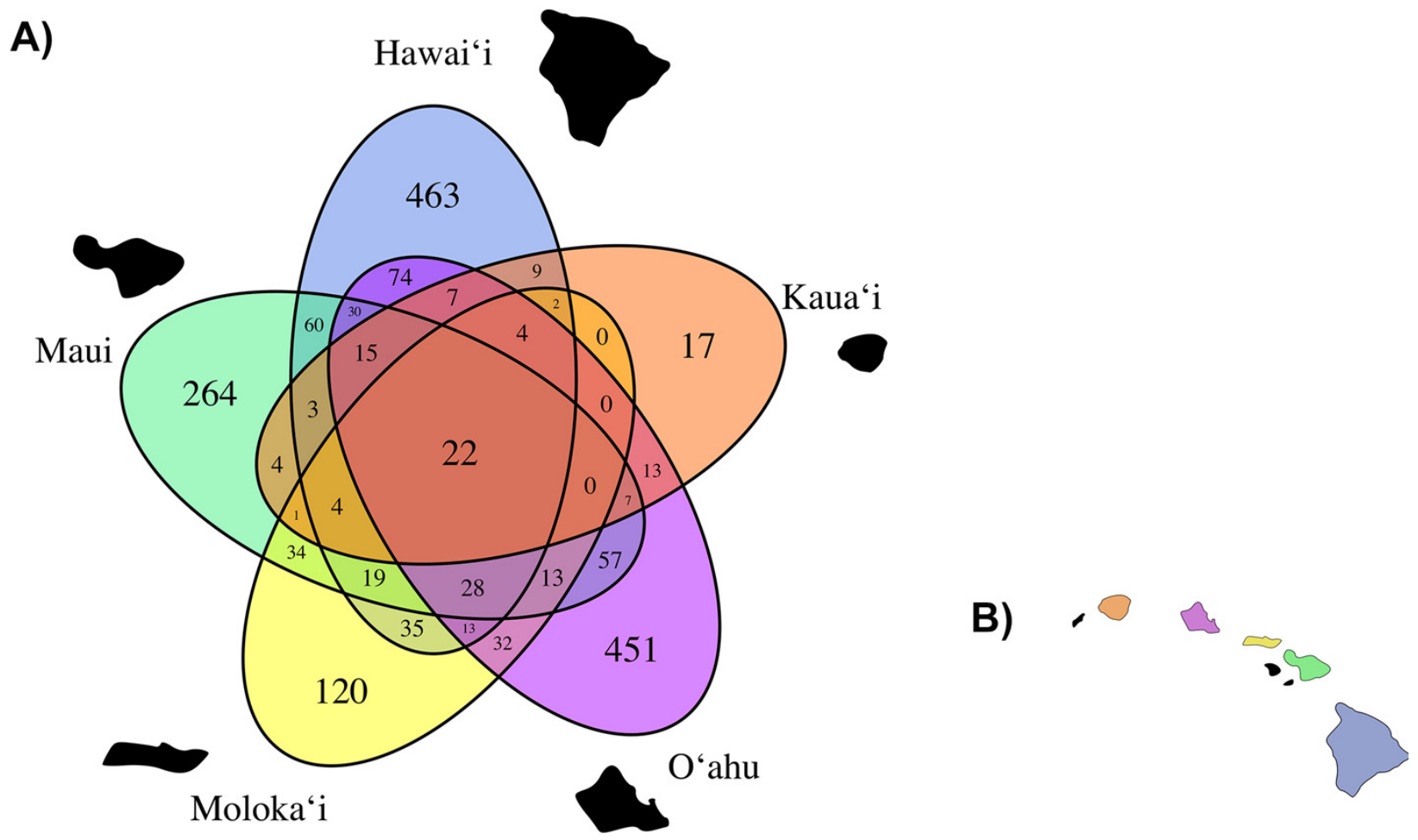

Figure 4: (A) A Venn Diagram displaying the number of overlapping fungal OTUs shared between Clermontia samples from each of the five main Hawaiian Islands, represented by a different color. The number of OTUs unique to each island lie on the outermost portion of each ellipse. (B) The geographic layout of the main Hawaiian Islands. 


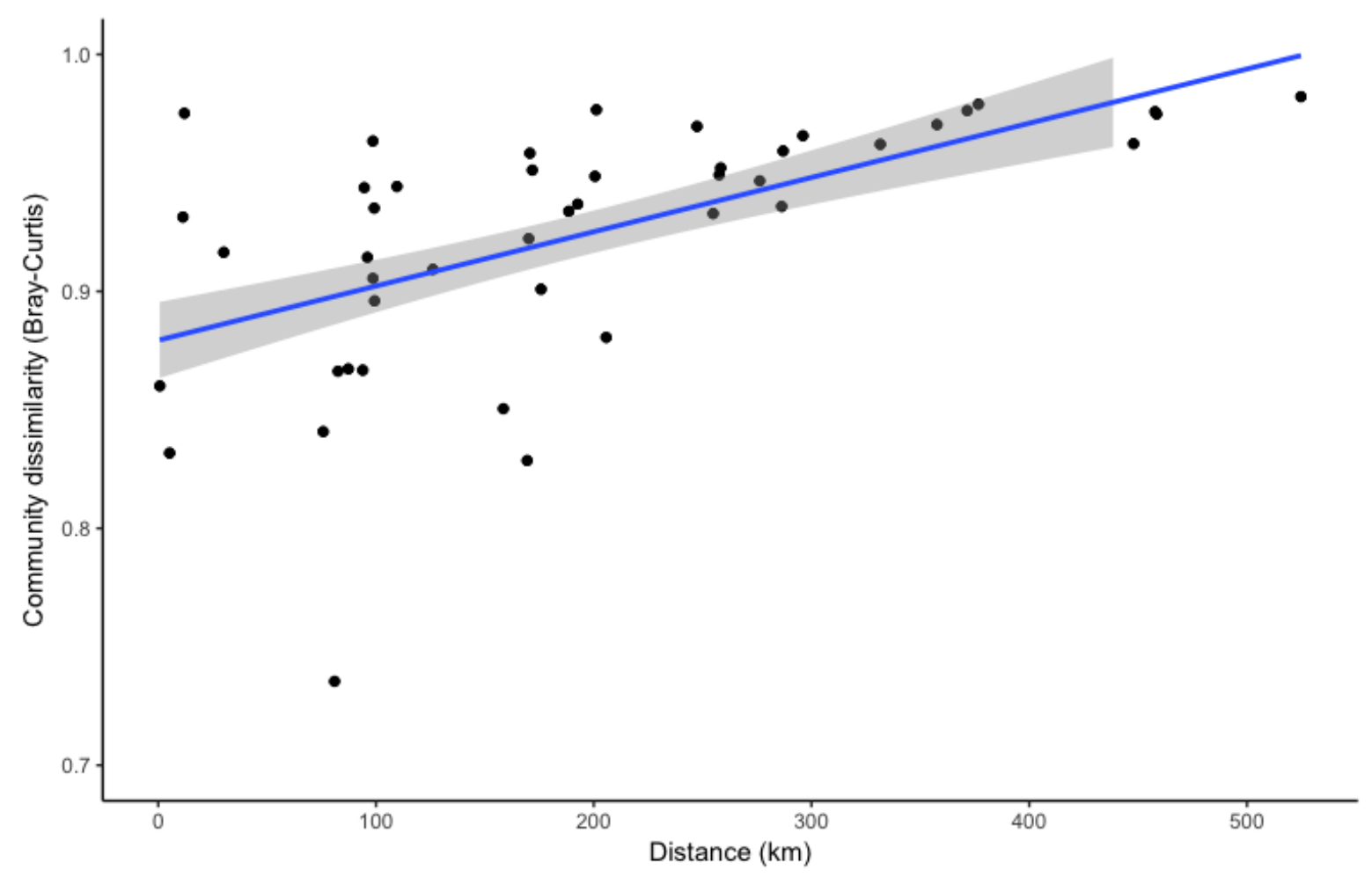

Figure 5: Pair-wise Bray-Curtis fungal community dissimilarity plotted against corresponding 599 pair-wise physical distances for each Clermontia plant bank sample spanning the main Hawaiian 600 Islands. A regression line was fit to the data, shown in blue, with $95 \%$ confidence intervals 601 shown in grey. (Partial Mantel test: $r=0.424, p=0.005$, accounting for time between sample 602 collection in days). 